10 - ORIGINAL ARTICLE

CLINICAL INVESTIGATION

\title{
Structural study of endopelvic fascia in prostates of different weights. Anatomic study applied to radical prostatectomy ${ }^{1}$
}

\author{
Helce Riberio Julio Junior ${ }^{\mathrm{I}}$, Suelen Freitas Costa ${ }^{\mathrm{I}}$, Waldemar Silva Costa ${ }^{\mathrm{II}}$, Francisco Jose Barcellos Sampaio ${ }^{\mathrm{III}}$, Luciano Alves \\ Favorito $^{\text {IV }}$
}

DOI: http://dx.doi.org/10.1590/S0102-8650201500400000010

${ }^{\mathrm{I}}$ Fellow PhD degree, Postgraduate Program in Fisiopathology and Surgical Sciences, Urogenital Research Unit, State University of Rio de Janeiro (UERJ), Brazil. Technical procedures, manuscript preparation.

IIAssociate Professor, Urogenital Research Unit, UERJ, Rio de Janeiro-RJ, Brazil. Supervised all phases of the study.

IIIFull Professor and Chief, Urogenital Research Unit, UERJ, Rio de Janeiro-RJ, Brazil. Design of the study.

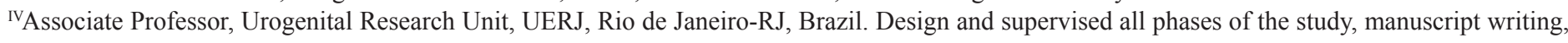
critical revision.

\section{ABSTRACT}

PURPOSE: To evaluate the structure of the endopelvic fascia in prostates of different weights.

METHODS: We studied 10 patients with BPH (prostates $>90 \mathrm{~g}$ ); 10 patients with prostate adenocarcinoma (PAC) (prostates $<60 \mathrm{~g}$ ) and five young male cadavers (control group). During the surgery a small sample of endopelvic fascia was obtained. We analyzed elastic fibers, collagen and smooth muscle. The stereological analysis was done with the Image Pro and Image J programs. Means were statistically compared using the one-way ANOVA with the Bonferroni test and a $\mathrm{p}<0.05$ was considered statistically significant.

RESULTS: The mean of the prostate weight was $122 \mathrm{~g}$ in BPH patients, 53.1g in PAC patients and 18.6g in control group. Quantitative analysis documented that there are no differences $(\mathrm{p}=0.19)$ in $\mathrm{Vv}$ of elastic fibers and in $\mathrm{Vv}$ of type III collagen $(\mathrm{p}=0.88)$ between the three groups. There was a significant difference $(\mathrm{p}=0<0.0001)$ in the quantification of SMC in patients with prostates $>90 \mathrm{~g}(\mathrm{mean}=9.61 \%)$ when compared to patients with prostates $<60 \mathrm{~g}$ (mean=17.92\%) and with the control group (mean=33.35\%).

CONCLUSION: There are differences in endopelvic fascia structure in prostates $>90 \mathrm{~g}$, which can be an additional factor for preoperatory evaluation of radical prostatectomy.

Key words: Prostate. Prostatectomy. Histology. 


\section{Introduction}

The endopelvic fascia is the outer layer of the parietal pelvic fascia $^{1}$. It covers the obturator internus, piriformis, levator ani and coccygeus muscles, is continuous with the transversalis fascia and is fused to the periosteum of the pubic bone ${ }^{1}$. Knowledge and proper identification of the pelvic fascias during radical prostatectomy is very important to enable the surgeon to preserve the nerve structures and consequently maintain the patient's potency and urinary continence ${ }^{2}$.

Recent studies have shown that preservation of the endopelvic fascia allows earlier recovery of urinary continence ${ }^{3,4}$, which is explained by the small distance between the endopelvic fascia and the nerves going to the rabdosphincter ${ }^{3}$ and also because the endopelvic fascia is close to the neurovascular bundle ${ }^{5}$

Although there have been several structural studies of the endopelvic fascia and its relation with incontinence e prolapse in women $^{6,7}$, studies of the endopelvic fascia in men are rare ${ }^{8}$. Despite indications that preservation of the endopelvic fascia during robotic prostatectomies results in improved continence, there are not published studies analyzing the relation between structural features of the endopelvic fascia and prostate weight.

However, it was observed that the weight of the prostate is significantly related to the prevalence of urinary incontinence in post-operative patients undergoing radical prostatectomy ${ }^{9}$.

The objective of this study is to analyze the structure of the endopelvic fascia in patients with prostate weight below 60 grams, above 90 grams and in young cadavers and to ascertain whether larger prostates cause structural alterations in the endopelvic fascia which can lead to urinary incontinency after radical prostatectomy.

\section{Methods}

This study was carried out in accordance with the ethical standards of the hospital's institutional committee on human experimentation.

We studied 10 patients with benign prostatic hyperplasia (BPH) (54 to 82 years old, mean=67.7) submitted to open retropubic prostatectomies and with prostates heavier than 90 grams $(\mathrm{g}) ; 10$ patients with prostate adenocarcinoma (PAC) (56 to 70 years old, mean=63.9) submitted to open radical prostatectomy and with prostates weighing under 60g; and five young male cadavers that were dissected and had small prostates (less than $30 \mathrm{~g}$ ). The endopelvic fascia was dissected during the surgeries and a small sample was obtained for histological analysis. The weight of the adenoma in BPH patients, PAC patients and cadavers was determined with a precision scale.

The endopelvic fascia was separated from the other structures and fixed in 10\% buffered formalin, and routinely processed for paraffin embedding, after which $5-\mu \mathrm{m}$ thick sections were obtained at $200-\mu \mathrm{m}$ intervals. Smooth muscle and connective tissue, elastic system fibers and collagen were studied by histochemical and immunohistochemical methods.

Sections were stained with hematoxylin-eosin to assess the integrity of the tissue. The following staining methods were used: Masson's trichrome, to quantify connective and smooth muscle tissue; Weigert resorcin fuchsin with previous oxidation to observe elastic system fibers; and picrosirius red with polarization for observation of different collagen types. The immunohistochemical analysis of type III collagen was was done with the avidin biotin (ABC) method with positive and negative controls (mouse monoclonal collagen III ABCAM).

Connective tissue, smooth muscle tissue and elastic system fibers were quantified by a stereological method ${ }^{10,11}$. This involved observation of five microscopic fields chosen at random, for a total of 25 test areas studied for each endopelvic fascia for the quantitative analysis. We used the Image J software, version 1.46r, loaded with its own plug-in (http://rsb.info.nih.gov/ij/). All sections were photographed with a digital camera (DP70, Olympus America, Inc., Melville, New York) under the same conditions at a resolution of 2.040 pixels, directly coupled to the microscope (BX51, Olympus America, Inc.) and stored in a TIFF file. To quantify the smooth muscle tissue, we used the Color Segmentation function of the Image $\mathrm{J}$ software, where the program selects structures of different colors and calculates the amount of each component.

To quantify the elastic fibers and collagen, we used the Image $J$ software to determine the volumetric density $(\mathrm{Vv})$ of each component (Figure 1).

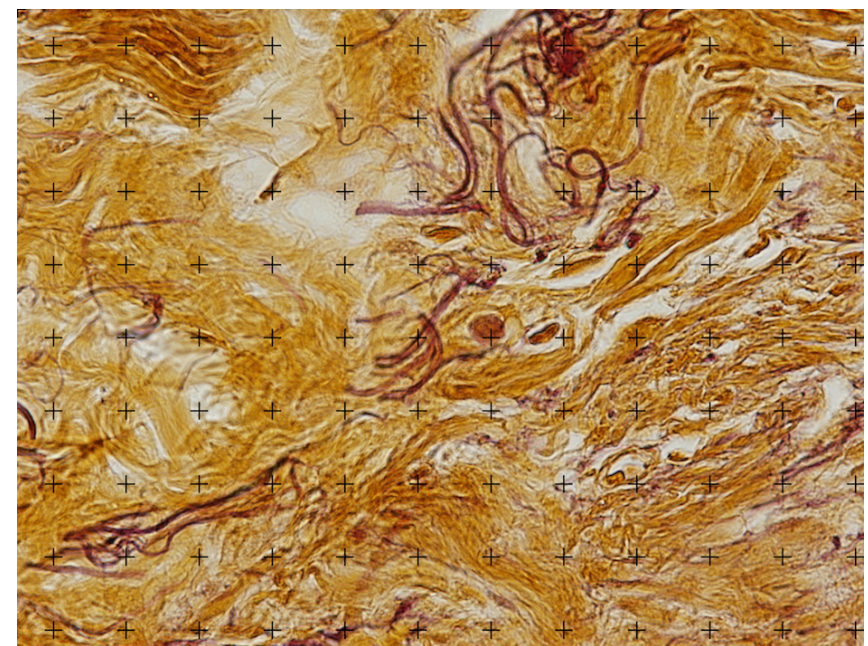

FIGURE 1 - Morphometric analysis of the endopelvic fascia. The photomicrograph shows the quantification of elastic fibers of the endopelvic fascia in a prostate heavier than $90 \mathrm{~g}$ using the Image J Test grid software (Weigert stain x200). 
Results for each field were obtained through the quantification assessment method, by superimposing a 100-point test grid (multipurpose test system) on the video monitor screen. The arithmetic mean of the quantification in five fields of each section was determined. Afterwards, we obtained the mean quantification value for the five sections studied from each endopelvic fascia fragment (total of 25 test areas).

Means were statistically compared using the one-way ANOVA with the Bonferroni test and a $\mathrm{p}<0.05$ was considered statistically significant.

\section{Results}

The patients with BPH had prostate weights between 90 and $196 \mathrm{~g}$ (mean=122g), ranged in ages between 54 and 82 yearsold (mean=67) and had PSA values varying from 1.94 to $22 \mathrm{ng} /$ $\mathrm{dL}$ (mean=8.6). The patients CAP had prostate weights between 40 and $62 \mathrm{~g}$ (mean=42.3g), ranged in ages between 56 and 70 years-old (mean=64) and had PSA values from 6.18 to $32.94 \mathrm{ng} /$ $\mathrm{dL}$ (mean=11.89). The patients of the control group ranged in ages between 17 and 30 years old (mean=24.4) and had prostate weights between $14 \mathrm{~g}$ and $22 \mathrm{~g}$ (mean=18.6 g).

Quantitative analysis documented that $\mathrm{VV}$ of SMC were significantly smaller $(\mathrm{p}<0.0001)$ in patients with prostates $>90 \mathrm{~g}$

A

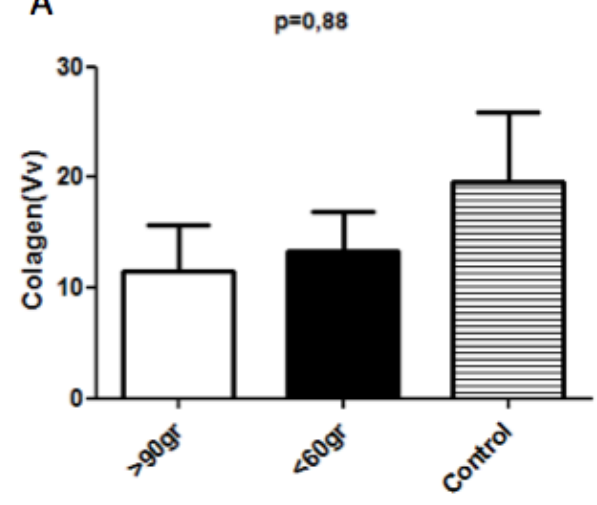

(mean $=9.61 \%, \mathrm{SD}=4.16 \%)$ when compared to patients with prostates $<60 \mathrm{~g}($ mean $=17.82 \%, \mathrm{SD}=5.08 \%)$ and with the control group (mean $=33.35 \%, \mathrm{SD}=3.44 \%$ ). The patients with prostates $<60$ g also had lower SMC values than the control group $(\mathrm{p}<0.0001)$.

Quantitative analysis documented no differences $(p=0.19)$ in $\mathrm{Vv}_{\mathrm{v}}$ of elastic fibers in patients with prostates $>90 \mathrm{~g}$ (mean=44.74\%; $\mathrm{SD}=26.46 \%$ ) when compared to patients with prostates $<60 \mathrm{~g}$ (mean $=49.67 \%, \mathrm{SD}=19.04 \%)$ and with the control group (mean $=27.73 \%, \mathrm{SD}=10.84 \%$ ).

Quantitative analysis also demonstrated no differences $(\mathrm{p}=0.88)$ in $\mathrm{Vv}$ of collagen III fibers in patients with prostates $>90 \mathrm{~g}$ (mean $=11.48 \% ; \mathrm{SD}=12.88 \%)$, in relation to the patients with prostates $<60 \mathrm{~g}$ (mean $=13.24 \%$; $\mathrm{SD}=11.44 \%)$ and with the control group (mean=19.56\%; $\mathrm{SD}=14.09 \%$ ). The patients with prostates $<60 \mathrm{~g}$ also did not present any difference in the quantity of collagen III fibers in comparison with the control group.

Picrosirius red with polarization photomicrographs revealed a difference in colors between the groups. There was predominance of green in the endopelvic fascia of the control group, suggesting type III collagen presence, and predominance of red in the endopelvic fascia in prostates with $>90 \mathrm{~g}$ and $<60 \mathrm{~g}$, suggesting type I collagen presence in these groups. The Figure 2 shows a graph of the quantification of elastic fibers, collagen and SMC.

B

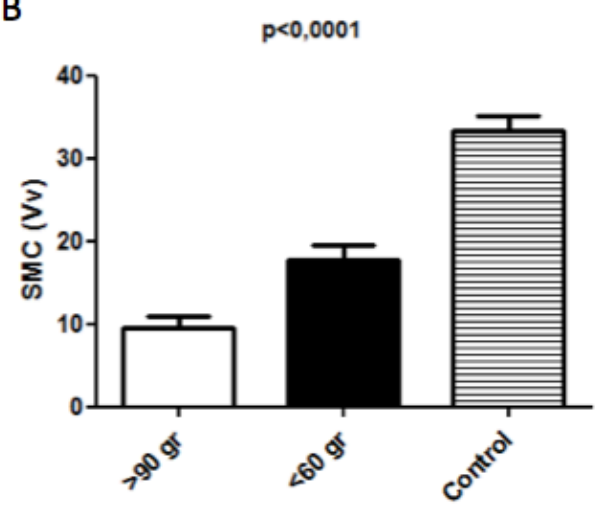

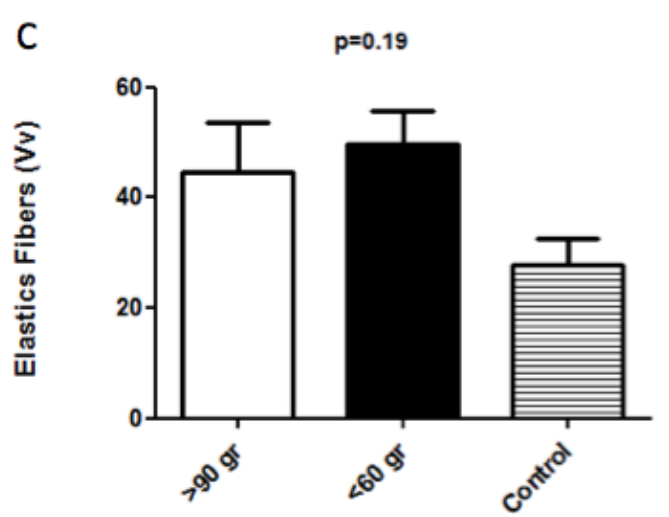

FIGURE 2 - Quantity of elastic fibers, SMC and collagen (Vv-volumetric density; SMC-smooth muscle fiber cells). 


\section{Discussion}

The thin fascia overlying the levator ani and lateral pelvic fascia represented the true endopelvic fascia. Previous studies have shown that the parietal fascia in a male's pelvis is a multilayered structure that comprises elastic fibers and smooth muscles ${ }^{8}$. The prostatic fascia is a multilayered connective tissue that comprises collagenous fibers, fat tissues, nerves and blood vessels. Laterally it fuses with the endopelvic fascia ${ }^{12-14}$.

One of the great merits of the advent of radical prostatectomy by laparoscopy and robotics is the better visualization of the structures during surgery, in contrast to open surgery, especially the ability to confirm the structure of the prostatic fascia. This enables the surgeon to select the best layer among the inter-fascial, intra-fascial or extra-fascial when a nervesparing procedure is carried out ${ }^{13}$. The positive relation between preserving the endopelvic fascia and postoperative continence and potency indices has been described recently ${ }^{3,5}$. The pubo-prostatic ligament-sparing procedure, carried out by avoiding incision of the endopelvic fascia, is expected to result in improved early postoperative recovery of continence and erectile function ${ }^{3,5}$.

The mean distance from the lowest point of the endopelvic fascia to the point where the sphincteric branch enters the rhabdosphincter was $5.5 \mathrm{~mm}^{3,5,15}$. Preservation of the fascia helps to protect the levator ani muscle, rhabdosphincter and pudendal nerve branches to the rhabdosphincter ${ }^{3,5,15}$. The current consensus, therefore, is that the neurovascular structures are located in the postero-lateral region of the prostate, at the confluence of Denonvilliers' fascia with the endopelvic and pararectal fascia ${ }^{12-14}$.

Intra-fascial dissection during radical prostatectomy allows better preservation of the sympathetic innervation but not of the parasympathetic fibers, without increasing surgical injuries of the prostate capsule ${ }^{16}$. The parietal and visceral endopelvic fascia is fused on the lateral side of the prostate and bladder. In this fusion, the levator fascia approaches the prostate and then turns back laterally ${ }^{12-14}$. This fusion site is sometimes recognized as a whitish line and is called the arcus tendineus fascia pelvis. An incision in the endopelvic fascia is necessary to confirm the presence of pre-rectal fat postero-lateral to the prostate in extrafascial dissection or non-nerve-sparing procedures ${ }^{12}$.

Previous studies have investigated the relation of the prostate size and, histopathological parameters and techniques during radical prostatectomy. Patients submitted to radical prostatectomy who have enlarged prostates have a greater chance of presenting aggressive prostate cancer and higher rates of urinary incontinence after surgery ${ }^{9,17}$. Larger prostates can lead to changes in the apical anatomy that can hamper dissection during the radical prostatectomy ${ }^{9,18}$. The shape and size of the prostate can significantly modify the anatomy of the NVB, urethral sphincter, dorsal vascular complex and pubovesical/puboprostatic ligaments ${ }^{13,18}$. However, the relation between prostate size and the pelvic fascia structure has never been described before.

In our sample we did not observe differences in distribution and quantification of elastic fibers between the three groups, despite the lower quantity of elastic fibers in the endopelvic fascia of the control group. The increased synthesis of elastic fibers may be associated with excessive distension of an organ or structure, as this also occurs in the vesical tissue during bladder outlet obstruction ${ }^{19,20}$. The increased concentration of elastic fibers in prostates weighing more than 40 grams, although not significant, might be an indication of a distension process in the pelvic fascias due to prostate enlargement.

We observed a decrease in the quantity of smooth muscle fibers in the patients with prostates $>90 \mathrm{~g}$ in relation to the control group and also in relation to the prostates weighing $<$ than $60 \mathrm{~g}$. We can speculate that smooth muscle fiber reduction is the primary event in fibrotic tissue formation, as described previously ${ }^{21}$. This event in our study is probably correlated to a distension process in the pelvic fascias, which occurs because of prostate enlargement or muscle atrophy that can lead to urinary incontinency.

It has been variously shown that a shift towards greenish color in the picrosirius polarization method is associated with less organized and/or degraded collagen ${ }^{22}$. In our sample, we observed a predominance of type III collagen in the control group. In earlier phases of the remodeling and repair of connective tissues, the synthesis of type III collagen is enhanced. Thus, based on these findings, the results of the collagen structure suggest that the collagen matrix of the bigger prostates is disrupted or degraded rather than fibrotic, a finding that is consistent with higher hydrostatic pressure. However, the quantitative analysis of type III collagen did not show a significant change between the three groups, although the control group also a higher concentration of type III collagen in the quantitative analysis.

The main limitations of this study were the technical impossibility of measuring the quantity of type I collagen and the small control group sample, due to the difficulty of obtaining suitable cadavers.

\section{Conclusion}

There are important structural differences in the endopelvic fascia in larger prostates, which can be another factor 
in preoperative evaluation of radical prostatectomy and that can predict increased chance of urinary incontinence.

\section{References}

1. Raychaudhuri B, Cahill D. Pelvic fasciae in urology. Ann R Coll Surg Engl. 2008 Nov;90(8):633-7. doi: 10.1308/003588408X321611.

2. Cornu JN, Phé V, Fournier G, Delmas V, Sèbe P. Fascia surrounding the prostate: clinical and anatomical basis of the nerve-sparing radical prostatectomy. Surg Radiol Anat. 2010 Aug;32(7):663-7. doi: 10.1007/s00276-010-0668-7.

3. Takenaka A, Hara R, Soga H, Murakami G, Fujisawa M. A novel technique for approaching the endopelvic fascia in retropubic radical prostatectomy, based on an anatomical study of fixed and fresh cadavers. BJU Int. 2005 Apr;95(6):766-71. PMID: 15794779.

4. Vora AA, Dajani D, Lynch JH, Kowalczyk KJ. Anatomic and technical considerations for optimizing recovery of urinary function during robotic-assisted radical prostatectomy. Curr Opin Urol. 2013 Jan;23 (1):78-87. doi: 10.1097/MOU.0b013e32835b0ae5.

5. Takenaka A, Tewari AK, Leung RA, Bigelow K, El Tabey N, Murakami G, Fujisawa M. Preservation of the puboprostatic collar and puboperineoplasty for early recovery of urinary continence after robotic prostatectomy: anatomic basis and preliminary outcomes. Eur Urol. 2007 Feb;51(2):433-40. PMID: 16904817.

6. Cör A, Barbic M, Kralj B. Differences in the quantity of elastic fibres and collagen type I and type III in endopelvic fascia between women with stress urinary incontinence and controls. Urol Res. 2003 Jun;31(2):61-5. PMID: 12677309.

7. Klutke J, Ji Q, Campeau J, Starcher B, Felix JC, Stanczyk FZ, Klutke C. Decreased endopelvic fascia elastin content in uterine prolapse. Acta Obstet Gynecol Scand. 2008;87(1):111-5. PMID: 18158636.

8. Hirata E, Fujiwara H, Hayashi S, Ohtsuka A, Abe S, Murakami G, Kudo Y. Intergender differences in histological architecture of the fascia pelvis parietalis: a cadaveric study. Clin Anat. 2011 May;24(4):469-77. doi: 10.1002/ca.21042.

9. Skeldon SC, Gani J, Evans A, Van Der Kwast T, Radomski SB. Striated muscle in the prostatic apex: does the amount in radical prostatectomy specimens predict postprostatectomy urinary incontinence? Urology. 2014 Apr;83(4):888-92. doi: 10.1016/j. urology.2013.12.055.

10. Chagas MA, Babinski MA, Costa WS, Sampaio FJ. Stromal and acinar components of the transition zone in normal and hyperplastic human prostate. BJU Int. 2002 May;89(7):699-702. PMID: 11966627.

11. Cavalcanti AG, Costa WS, Baskin LS, McAninch JA, Sampaio FJ. A morphometric analysis of bulbar urethral strictures. BJU Int. 2007 Aug;100 (2):397-402. PMID: 17617144.

12. Hinata N, Sejima T, Takenaka A. Progress in pelvic anatomy from the viewpoint of radical prostatectomy. Int J Urol. 2013 Mar;20(3):26070. doi: 10.1111/iju.12021.

13. Walz J, Burnett AL, Costello AJ, Eastham JA, Graefen M, Guillonneau B, Menon M, Montorsi F, Myers RP, Rocco B, Villers A. A critical analysis of the current knowledge of surgical anatomy related to optimization of cancer control and preservation of continence and erection in candidates for radical prostatectomy. Eur Urol. 2010 Feb;57(2):179-92. doi: 10.1016/j.eururo.2009.11.009.

14. Patel VR, Schatloff O, Chauhan S, Sivaraman A, Valero R, Coelho RF, Rocco B, Palmer KJ, Kameh D. The role of the prostatic vasculature as a landmark for nerve sparing during robot-assisted radical prostatectomy. Eur Urol. 2012 Mar;61(3):571-6. doi: 10.1016/j.eururo.2011.12.047.
15. Tewari A, Takenaka A, Mtui E, Horninger W, Peschel R, Bartsch G, Vaughan ED. The proximal neurovascular plate and the tri-zonal neural architecture around the prostate gland: importance in the athermal robotic technique of nerve-sparing prostatectomy. BJU Int. 2006 Aug;98(2):314-23. PMID: 16879671.

16. Rifaloglu MM, Davarci M, Ozgur T, Ozkanli S, Ozdes MI, Onem K, Balbay MD. Histopathologic evaluation of neurovascular bundles and periprostatic tissue in interfascial and intrafascial nerve-sparing radical prostatectomy technique: a cadaveric anatomic study. Urol. 2013 Oct;82(4):948-54. doi: 10.1016/j.urology.2013.06.012.

17. Hong SK, Poon BY, Sjoberg DD, Scardino T, Eastham JA. Prostate size and adverse pathologic features in men undergoing radical prostatectomy. Urology. 2014 Jul;84(1):153-7. doi: 10.1016/j. urology.2014.04.006.

18. Myers RP, Goeliner JR, Cahil DR. Prostate shape external striated urethral sphincter and radical prostatectomy: the apical dissection. J Urol. 1987 Sep;138(3):543-50. PMID: 3625855.

19. Cortivo R, Pagano F, Passerini G, Abatangelo G, Castellani I. Elastin and collagen in the normal and obstructed urinary bladder. Br J Urol. 1981 Apr;53(2):134-7. PMID: 7237045.

20. Gosling JA. Modification of bladder structure in response to outflow obstruction and ageing. Eur Urol. 1997;32 (suppl 1):9-14. PMID: 9218937.

21. Tostes GD, Costa SF, Carvalho JP, Costa WS, Sampaio FJ, Favorito LA. Structural analysis of testicular appendices in patients with cryptorchidism. Int Braz J Urol. 2013 Mar-Apr;39(2):240-7. doi: 10.1590/S1677-5538.

22. Ushiki T. Collagen fibers, reticular fibers and elastic fibers. A comprehensive understanding from a morphological viewpoint. Arch Histol Cytol. 2002 Jun;65(2):109-26. PMID: 12164335.

\section{Correspondence:}

Luciano Alves Favorito

Rua Professor Gabizo, 104/201

20271-320 Rio de Janeiro - RJ Brasil

Tel.: (55-21)2264-4679

Fax: (55-21)3872-8802

lufavorito@yahoo.com.br

Received: Dec 10, 2014

Review: Feb 11, 2015

Accepted: Mar 12, 2015

Conflict of interest: none

Financial source: National Council for Scientific and Technological Development $(\mathrm{CNPq})$ and Rio de Janeiro State Research Foundation (FAPERJ)

${ }^{1}$ Research performed at Urogenital Research Unit, State University of Rio de Janeiro (UERJ), Brazil. 